\title{
A REDUÇÃO ONTOLÓGICA DO HOMEM À MÁOUINA EM MARX: subsídios ao debate contemporâneo
}

Alessandro de Melo*

RESUMO: Este artigo pretende ser mais um elemento de debate sobre as contribuições de Marx para a compreensão e a crítica da sociedade atual, caracterizada, em termos econômicos, pelo avanço do neoliberalismo e da acumulação flexível da produção. Partindo desse pressuposto, pretende-se verificar, na obra O Capital, o movimento histórico de desqualificação dos trabalhadores no desenvolvimento das forças produtivas no capitalismo, nas suas fases da cooperação, manufatura e maquinaria e grande indústria. Esses elementos históricos são compreendidos aqui pelo conceito de redução ontológica, ou seja, a redução do homem, do trabalho e da sociedade em mera determinação econômica. Tal redução elimina ideologicamente os elementos da realidade como condição de desenvolvimento do capital, elementos estes que são os que lhe deram origem e o sustentam.

Palavras-Chave: Redução Ontológica; Trabalho e Educação; Desqualificação dos Trabalhadores.

\section{THE ONTOLOGICAL REDUCTION OF MAN TO MACHINE IN MARX:} SUBSIDIES FOR CONTEMPORARY DEBATE

ABSTRACT: This essay intends to be one more element of a debate about Marx's contributions for the understanding and critic of the current society, which is characterized in economic terms by the progress of neoliberalism and the flexible accumulation of production. About this initial presupposition, the text intends to verify the book "The Capital" the historical movement of workers' disqualification in the development of the productive forces in the capitalism: in its phases of cooperation, manufactures and machinery and big industry. These historicall elements are understood here by the concept of ontological reduction, that means the men, human work, as well as the whole society reduction only to economic determination. This reduction eliminates ideologically the elements of reality as a capital development condition. Those elements are the capital origin and its support.

Keywords: Ontological Reduction; Work and Education; Worker's Disqualification.

* Mestre em Educação Escolar pela Universidade Estadual Paulista (UNESP) Faculdade de Ciências e Letras de Araraquara e Doutorando em Educação pela Universidade Federal do Paraná (UFPR). Professor na Universidade Estadual do CentroOeste (UNICENTRO).E-mail: alessandrodemelo2006@hotmail.com 


\section{INTRODUCุÃO}

Pretende-se discutir a possibilidade metodológica do retorno à análise marxiana da (de)formação dos homens enquanto trabalhadores no sistema capitalista de produção. Este retorno tem o duplo sentido de provar a força dos argumentos de Marx para a compreensão da atualidade, que, na produção, é caracterizada pelo fenômeno da acumulação flexível (HARVEY, 2002). Esta abordagem pretende se constituir como mais uma ferramenta de debate contra os princípios pós-modernos, para os quais o marxismo está acabado como forma de explicação, assim como a possibilidade de racionalizar a realidade, que se torna um esforço inútil perante suas novas configurações como sociedade do conhecimento, sociedade da informação, sociedade das imagens, etc. (EVANGELISTA, 1997).

Por outro lado, pretende-se trabalhar com o conceito de "redução ontológica", de Oliveira (2004), que, apoiado nos princípios marxianos, explica essa (de)formação humana no capitalismo como resultante da redução das esferas sociais à pura determinação econômica. Nesse movimento de redução da qualidade para a quantidade, do valor de uso para o valor de troca, do trabalho útil para o trabalho abstrato, o homem fica reduzido em seu estatuto ontológico como ser econômico, como mera força de trabalho, o que é evidenciado pela constatação de Marx de que, no capitalismo, o homem transforma-se em "órgão" da máquina.

Este pequeno estudo pretende dar suporte para a compreensão das relações contemporâneas do mundo do trabalho e da formação dos trabalhadores, hoje baseada no conceito de "flexibilização" (HARVEY, 2002; KUENZER, 2002; 2003), aqui entendida como mais uma faceta da redução ontológica na contemporaneidade.

Na primeira parte do texto, faz-se uma retomada dos capítulos XI, XII e XIII de O Capital, em que Marx analisa a cooperação, a manufatura e a maquinaria e a grande indústria, com o objetivo de averiguar como o autor considera a (des)qualificação dos trabalhadores em cada período.

$\mathrm{Na}$ segunda parte, retoma-se o conceito de redução ontológica, de Oliveira (2004), para entender o mesmo processo como uma mudança no estatuto ontológico do homem, pela sua redução a um quantum econômico. 
$\mathrm{Na}$ terceira parte, serão abordadas as questões pertinentes à redução ontológica no campo da educação, referente ao conceito de competências, e, no campo estrito do trabalho, com relação ao conceito de empregabilidade. Para isso, e de forma breve, utilizamos como fontes principais os documentos da CNI $(1993 ; 2007)$ e alguns argumentos dos principais autores que tratam da corrente subjetivista da educação, ou seja, o construtivismo e a relação deste com a pedagogia das competências (DUARTE, 2000; RAMOS, 2001; 2001a; SILVA, 2007). O objetivo, neste caso, é defender a relação entre as demandas dos industriais e a pedagogia das competências como forma de redução ontológica do homem a mera força de trabalho.

Como se trata de um estudo específico sobre os capítulos mencionados de O Capital e também do livro de Oliveira (2004), ao longo do texto outros autores serão referenciados apenas quando analisam esses livros ou por auxiliarem em discussões pertinentes ao alargamento do campo aqui estudado.

\section{A CAPTURA DO TRABALHADOR PARA A PRODUCְÃO}

No Livro I d'O Capital (MARX, 1998), Marx analisa o movimento histórico de consolidação do capitalismo nas fases de desenvolvimento da produção, desde a cooperação (Capítulo XI), passando pela manufatura (Capítulo XII), até a maquinaria e a indústria moderna (Capítulo XIII). Para o que interessa aos limites deste artigo, será focalizado o movimento geral em relação à desqualificação do trabalhador que, em resumo, deixa de ter, fazer e conhecer os meios e o processo global de produção, destinado então a executar apenas tarefas parciais na produção. Segundo Klein:

a organização do trabalho, sob o capital, obedece a uma lógica que se caracteriza pela constituição, cada vez mais desenvolvida, do trabalhador coletivo, entendido enquanto somatório de inúmeros trabalhadores parciais (ou seja, trabalhadores que realizam apenas uma parcela das atividades que compõem o processo integral de produção de um dado produto). (KLEIN, 2003, p. 21)

O caminho para a formação do trabalhador coletivo teve seu início na primeira forma capitalista de produção, a cooperação, a que 
Marx acentua como sendo a primeira fase da produção capitalista (MARX, 1998, p. 375). Nessa fase inicial, a produção ainda não se distinguia do processo artesanal, a não ser pelo importante fato de que agora os artesãos, destituídos da propriedade dos meios de produção, passaram a vender sua força de trabalho a um capitalista, que os organiza numa oficina, utilizando basicamente os mesmos métodos de produção. Nas palavras de Marx:

[...] a produção capitalista só começa realmente quando um mesmo capital particular ocupa, de uma só vez, número considerável de trabalhadores, quando o processo de trabalho amplia sua escala e fornece produtos em maior quantidade. A atuação simultânea de grande número de trabalhadores, no mesmo local, ou, se se quiser, no mesmo campo de atividade, para produzir a mesma espécie de mercadoria sob o comando do mesmo capitalista constitui, histórica e logicamente, o ponto de partida da produção capitalista. (MARX, 1998, p. 375)

Cria-se, na cooperação, uma força nova, de caráter coletivo e que consegue revolucionar o modo de produção em relação ao artesanato. Uma mudança substancial quanto a esse aspecto dá-se pelo rompimento com o valor da mercadoria, que, no artesanato, era calculado pelo tempo de trabalho do artesão individualmente. Nas oficinas organizadas pelo capitalista, passa a valer o tempo de trabalho médio como valor da mercadoria, ou seja, não é mais a destreza individual o parâmetro para conferir valor à mercadoria, mas sim a destreza média.

Essa modificação coloca para a concorrência capitalista o grande paradigma, ou seja, se existe na sociedade um tempo médio de produção de determinada mercadoria, os capitalistas individualmente devem se colocar na concorrência conforme esse tempo médio. Segundo Marx (1998, p. 377), "A lei da produção do valor só se realiza plenamente para o produtor individual quando produz como capitalista, empregando, ao mesmo tempo, muitos trabalhadores, pondo em movimento, desde o começo, trabalho social médio".

Marx quis com isso dizer que, no capitalismo, não é dada a possibilidade da livre escolha do capitalista sobre o modo como deseja produzir. Para que possa se constituir como concorrente e, logo, reproduzir-se como tal, cada capitalista precisa, necessariamente, produzir conforme a média do trabalho social, determinado pelo desenvolvimento 
das forças produtivas do período histórico em que se encontra produzindo e concorrendo. Afirmamos que essa condição é paradigmática porque, na verdade, revela o movimento real do capitalismo em todo o seu processo de desenvolvimento.

Voltando ao texto de Marx, ressalta-se que, juntamente com essas modificações dadas em termos estruturais quanto à produção capitalista na cooperação, a figura do trabalhador coletivo é igualmente gestada. Esse movimento histórico é muito bem-captado pelo autor quando ele diz que, na cooperação, "[...] desfaz-se o trabalhador dos limites de sua individualidade e desenvolve a capacidade de sua espécie" (MARX, 1998, p. 382).

Nessa passagem, está exposta a contradição central do trabalho no capitalismo, ou seja, de um lado, encontra-se um elemento de sua positividade, que é a possibilidade dada ao trabalho coletivo de poder libertar o homem das amarras naturais, estritamente biológicas, pela possibilidade de produzir condições materiais de vida em larga escala e, ao mesmo tempo, o elemento de sua negatividade, ou seja, a própria materialidade do regime capitalista em que essa potencialidade ocorre, que não tem por objetivo a coletivização dos produtos do trabalho humano, mas a acumulação de capitais e a reprodução do sistema que a possibilita. Todo o restante do sistema é subordinado a esse objetivo.

Desse modo, como aponta Kuenzer (1985, p. 48), desde o princípio a relação entre capital e trabalho se verificou pela heterogestão ou, nas palavras de Marx (1998, p. 385), “[...] uma vontade alheia que subordina a um objetivo próprio a ação dos assalariados”. Desde a cooperação, portanto, a motivação e a conexão dos trabalhos na produção de mercadorias são externas aos trabalhadores, pertencem ao capital, que ainda ganha gratuitamente a força coletiva gerada no processo de produção, pois o pagamento é dado apenas aos trabalhadores isolados. Vejamos mais de perto como isso ocorre nas palavras de Marx (1998, p. 382): "Comparando-se com uma soma igual de jornadas de trabalho individuais, isoladas, produz a jornada de trabalho coletiva maiores quantidades de valor-de-uso e reduz, por isso, o tempo de trabalho necessário para a produção de determinado efeito útil”.

Daí que, até mesmo na forma de pagamento da força de trabalho, o capital acaba ganhando pela gestão coletiva do trabalho unificado na grande oficina. Ademais, esse traço é apenas reforçado pelo 
desenvolvimento tecnológico, que gera a multiplicação geométrica da capacidade coletiva de produzir, o que não é refletido no pagamento, aumentando sobremaneira a exploração da mais-valia relativa.

A fase seguinte à cooperação, a manufatura, que Marx denomina de "a forma clássica da cooperação", perdurou entre os séculos XIV e XVIII. A manufatura tem como formato o processo produtivo parcelizado, ou seja, os trabalhadores de ofícios diversos, reunidos numa mesma oficina, fazem cada qual certa parcela do produto final. Até aí não há uma ruptura com o sistema da cooperação simples, ao contrário, é mesmo sua continuação mais desenvolvida. O que Marx observa como característico dessa fase é que nela se inicia a especialização das atividades, ou seja, aquele artesão que antes dominava toda a extensão de seu ofício, quando colocado a trabalhar numa atividade específica, perde com o tempo a capacidade que tinha de domínio de todo o ofício anterior. Marx dá um clássico exemplo desse processo:

O costureiro, o serralheiro, o correeiro etc. que se ocupam apenas com a feitura de carruagens perdem pouco a pouco, com o costume, a capacidade de exercer seu antigo ofício em toda a extensão. Além disso, sua atividade especializada assume a forma mais apropriada a essa esfera restrita. No início, a manufatura de carruagens era uma combinação de ofícios independentes. Progressivamente, ela se transformou num sistema que divide a produção de carruagens em suas diversas operações especializadas; cada operação se cristaliza em função exclusiva de um trabalhador e a sua totalidade é executada pela união desses trabalhadores parciais. (MARX, 1998, p. 391-392)

Embora reconheçamos que o desenvolvimento da produção capitalista tomou proporções talvez não imaginadas no século XIX, mais especificamente também não imaginadas pelo autor de $O$ Capital, não podemos nos furtar de perceber que a apreensão do movimento da realidade da produção capitalista, nesse momento da ascensão da manufatura, é, de tal forma, densa e perspicaz que mantém certa atualidade. Quando Marx nos informa sobre a destituição do conhecimento da totalidade do ofício do artesão na passagem para a manufatura, em que se passa a executar não mais a atividade original, mas uma parcela do trabalho total, o autor está nos mostrando, na realidade, o princípio da constituição do trabalhador sob o capitalismo, o que, portanto, é válido para a compreensão da formação do trabalhador contemporâneo. 
Aqui, portanto, a produção social do trabalhador coletivo ganha fôlego ainda maior, pois que a especialização, como já advertira Adam Smith, carrega consigo grandes vantagens para a produtividade (SMITH, 1985).

$\mathrm{Na}$ formação do trabalhador para a manufatura, há a perda do domínio da totalidade do processo de trabalho artesanal, o que significa historicamente um importante processo de desqualificação dos trabalhadores, que se tornam órgãos do mecanismo de produção, como afirmou Marx. A virtuosidade do trabalhador na manufatura é uma virtuosidade parcial, que transforma o corpo do trabalhador em um órgão dessa atividade parcial.

A manufatura produz realmente a virtuosidade do trabalhador mutilado, ao reproduzir e levar sistematicamente ao extremo, dentro da oficina, a especialização natural dos ofícios que encontra na sociedade (MARX, 1998, p. 394).

Essa virtuosidade mutiladora do trabalhador é orgânica às necessidades do capital por maior produtividade, o que, sem dúvida, aconteceu devido à intensificação do trabalho, que é usado integralmente pelo capitalista, segundo o contrato de trabalho firmado pelas partes.

É na manufatura que emerge, com toda a força, o trabalhador coletivo, “[...] mecanismo específico do período manufatureiro" (MARX, 1998, p. 403). No conjunto do trabalhador coletivo, cada um era exigido em uma habilidade específica, como força, atenção, destreza, etc., para a qual desenvolviam sua virtuosidade. A diferenciação das tarefas entre os trabalhadores separa-os, genericamente, entre hábeis e inábeis. Para cada nível de tarefa é exigida uma qualificação diferenciada, que, por sua vez, passa a possuir valor diferenciado. É o princípio educativo da manufatura.

Em todo ofício de que se apossa, a manufatura cria uma classe de trabalhadores sem qualquer destreza especial, os quais o artesanato punha totalmente de lado. Depois de desenvolver, até atingir a virtuosidade, uma única especialidade limitada, sacrificando a capacidade total de trabalho do ser humano, põe-se a manufatura a transformar numa especialidade a ausência de qualquer formação. (MARX, 1998, p. 405)

Percebe-se, nesse trecho, que a exigência formativa advinda da produção é mínima e, de qualquer modo, essa formação não se vincula a conteúdos especializados, pois que o trabalho se aprende fazendo, pela repetição das tarefas e na intimidade do trabalhador com a ferramenta, relação esta que Marx caracterizou como a contradição da manufatura. 
$\mathrm{Na}$ produção manufatureira é também forjada, como fica evidenciado no trecho anterior, a hierarquização entre os trabalhadores, os chamados hábeis e inábeis. Mais que isso, o trabalho na manufatura, segundo Marx, deforma o trabalhador de forma "monstruosa", alijandoo de todo potencial e refreando seus instintos e capacidades produtivas. Esse alijamento, aliás, atinge a própria relação do trabalhador com o corpo, pois a divisão do trabalho passa a exigir do trabalhador o desenvolvimento e a atividade de apenas uma parte de seu corpo, que passa a ser, assim, deformado na produção.

A especialização, que historicamente foi forjada sobre a destituição dos conhecimentos dos trabalhadores, passa a ser o princípio de formação do trabalhador na indústria moderna. Logo, a falta de conhecimento torna-se especialização, afirma Marx. A virtuosidade mutilada do trabalhador reproduz a mutilação desse trabalhador em termos de sua formação. Esta, por sua vez, relaciona diretamente o trabalhador e sua ferramenta.

A manufatura se caracteriza pela diferenciação das ferramentas, que imprime aos instrumentos da mesma espécie formas determinadas para cada emprego útil especial, e pela especialização, que só permite a cada uma dessas ferramentas operar plenamente em mãos do trabalhador parcial específico. (MARX, 1998, p. 396)

Pelo exposto, a produtividade no trabalho manufatureiro dependia estritamente da virtuosidade mutilada do trabalhador em relação ao seu instrumento de trabalho, ao qual se somava como parte do processo maior de produção. $O$ trabalhador passava a se constituir, como já foi dito, órgão específico da produção.

Marx destaca que a manufatura não apenas forjou uma nova espécie de trabalho e de trabalhador, o trabalhador coletivo, mas também que a manufatura desenvolveu o sistema de produção social como um todo, interferindo inclusive na divisão social e territorial da produção. Nas suas palavras:

Sendo a produção e a circulação de mercadorias condições fundamentais do modo de produção capitalista, a divisão manufatureira do trabalho pressupõe que a divisão do trabalho na sociedade tenha atingido certo grau de desenvolvimento. Reciprocamente, a divisão manufatureira do trabalho, reagindo, desenvolve-se e multiplica a divisão social do trabalho. Com a 
diferenciação das ferramentas, diferenciam-se cada vez mais os ofícios que fazem essas ferramentas. [...] A divisão territorial do trabalho, que confina ramos particulares de produção em áreas determinadas de um país, recebe novo impulso com a atividade manufatureira, que explora todas as peculiaridades. (MARX, 1998, p. 408)

Portanto, não é somente no interior da produção que a manufatura causa impactos significativos, mas também no sistema de produção como um todo e na sociedade em geral, ao vincular seu desenvolvimento com certa divisão territorial e, logo, uma nova especialização espacial da produção, ligada à oferta de matérias-primas, de recursos naturais disponíveis, etc.

A formação do trabalhador para a manufatura, portanto, não é feita apenas para a divisão interna da produção, na oficina, mas também pela divisão territorial. Em determinadas regiões, passa a ser demandado certo tipo de trabalhador, diferente de outras demandas regionais, cuja base produtiva é diferenciada. Marx, assim, afirma que existe uma similaridade entre a divisão técnica do trabalho e a divisão social do trabalho.

Podemos, com A. Smith, imaginar que a divisão social do trabalho se distingue da divisão do trabalho na manufatura apenas subjetivamente, isto é, para o observador, que, na manufatura, vê em conjunto os diversos trabalhos parciais que se processam no mesmo local, enquanto a divisão do trabalho na sociedade tem sua conexão obscurecida por estar dispersa em imensas áreas e pelo grande número dos que estão ocupados em cada ramo determinado. (MARX, 1998, p. 409)

Outra marca indelével da produção capitalista é a dependência que o trabalhador passou a ter, especialmente após a manufatura, da compra da mão-de-obra pelo capitalista para que pudesse realizar a sua força de trabalho. Assim inicia-se a relação de dupla expropriação do trabalhador: de um lado, é expropriado de seus conhecimentos e ofícios anteriores; de outro, é expropriado da autonomia de trabalhar para si.

Da mesma forma, com a formação do trabalhador coletivo, a expropriação é ainda maior, pois a soma dos trabalhos parciais é toda ela revertida para o capital, que ainda fica com a mais-valia expropriada individualmente, o que lhe garante duplo ganho. Esse processo de expropriação é mais atual do que nunca com o advento da base 
microeletrônica. Ademais, já advertia Marx com relação ao processo da dinâmica histórica: "Excetuando-se aspectos acessórios, só existe mudança de forma quando sobrevém uma revolução nos instrumentos de trabalho" (MARX, 1998, p. 419). Daí a importância que estamos dando ao estudo do desenvolvimento histórico dos processos de produção, ou seja, acreditamos que é nesse desenvolvimento que se encontra a chave para o descortinamento das relações contemporâneas do trabalho, caracterizadas pela acumulação flexível.

Mas a manufatura, apesar do salto que deu na produção capitalista, especialmente quanto à radicalização do trabalhador coletivo e a sua constituição como modelo, ainda apresentava limites, como o fato de que o produto ainda tinha de passar de mão em mão no processo de produção, o que o tornava moroso e custoso. Esse aspecto negativo da manufatura torna impossível sua perpetuação como sistema de produção.

Além do fato de que a manufatura já não conseguia mais corresponder aos aumentos da demanda, o capital enxergava como um risco o processo de trabalho estar nas mãos dos trabalhadores. Como o capital mirava e mira a independência possível do trabalho vivo, e luta contra sua insubordinação (veja o massacre ao sindicalismo ao longo da história do capitalismo, por exemplo), a manufatura passou a ser um sistema arriscado.

No seio desse processo contraditório, na oficina manufatureira surgem as máquinas e sua generalização no processo produtivo, o que Marx caracteriza como uma nova fase do desenvolvimento capitalista, a maquinaria.

Essa oficina, produto da divisão manufatureira do trabalho, produziu, por sua vez, máquinas. Estas eliminaram o ofício manual como princípio regulador da produção social. Assim, não há mais necessidade técnica de fixar o trabalhador a uma operação parcial, por toda a vida. E caíram as barreiras que aquele princípio opunha ao domínio do capital. (MARX, 1998, p. 424)

O advento da maquinaria, estudada por Marx no Capítulo XIII de $O$ Capital, tem por objetivo tão-somente a maior exploração da maisvalia relativa, o que significa mais um passo para aquilo para o que vimos chamando a atenção neste texto, ou seja, para o fato de que o desenvolvimento das formas de produção capitalistas não é mais do que novas formas que o capital encontra para se apropriar desta mais-valia. 
Esse movimento constante na história do capitalismo, portanto, não se pode deixar de lado quando o objeto de estudo são as formas mais contemporâneas de extração da mais-valia relativa, por meio da forma flexível de produção baseada na microeletrônica.

Voltando à questão da maquinaria, ela revoluciona outro aspecto do trabalho, ou seja, nessa etapa, o centro da produção deixa de ser o trabalhador e converge para a máquina, que, por sua vez, tem outro princípio de funcionamento, conforme explica Marx (1998, p. 429):

Toda maquinaria desenvolvida consiste em três partes essencialmente distintas: o motor, a transmissão e a máquina-ferramenta ou máquina de trabalho. O motor é a força motriz de todo o mecanismo. [...] O motor e a transmissão existem apenas para transmitir movimento à máquinaferramenta, que se apodera do objeto de trabalho e o transforma de acordo com o fim desejado. É desta parte da maquinaria, a máquina-ferramenta, que parte a revolução industrial do século XVIII. (MARX, 1998, p. 429)

Acompanha esse novo mecanismo da máquina uma nova forma de expropriação do trabalhador. De forma genérica, o que acontece na maquinaria e na indústria moderna é que as máquinas "roubam" a já parcelada virtuosidade do manejo das ferramentas que se dava na manufatura, resultando em uma expropriação radical da formação do trabalhador pelo capital. A virtuosidade do trabalhador é repassada para a máquina, eliminando-se o inconveniente da insubordinação dos trabalhadores e a dependência do capital em relação às habilidades deles. Todo o trabalho realizado anteriormente pelo trabalhador está objetivado na máquina-ferramenta. ${ }^{1}$

A desvantagem do trabalhador é que ele é limitado a trabalhar com a quantidade de ferramentas para as quais o seu corpo físico é preparado. A máquina, por sua vez, inclui em seu funcionamento várias ferramentas ao mesmo tempo, permitindo com isso maior produtividade. A máquina se emancipa do homem com relação ao limite orgânico que este apresenta, desqualificando ainda mais o trabalho humano.

Quando o homem passa a atuar apenas como força motriz numa máquinaferramenta, em vez de atuar com a ferramenta sobre o objeto de trabalho, podem tomar seu lugar o vento, a água, o vapor etc., e torna-se acidental o emprego da força muscular humana como força motriz. (MARX, 1998, p. 431)

$\mathrm{O}$ autor de $\mathrm{O}$ Capital compreende que, nesta passagem do 
trabalho manual da manufatura e da cooperação para o trabalho na maquinaria, acontece uma revolução importante na relação entre o trabalhador e sua atividade. Antes, o trabalhador agia diretamente no produto, agora, com a máquina, passa a agir mediatamente, ou seja, intermediado pela ação da máquina, que passa a ser central no processo.

Para Klein (2003, p. 26), esse processo significa uma radicalização da desqualificação do trabalhador:

Desse modo, a indústria mecanizada promove um nivelamento dos trabalhos que os operários - agora meros auxiliares das máquinas - têm que executar e, assim, dissolve a hierarquia dos trabalhadores especializados. A fronteira entre os hábeis e os inábeis torna-se cada vez mais tênue, ampliando o contingente destes últimos. (KLEIN, 2003, p. 26).

A repercussão desse processo na sociedade se dá pelo aumento significativo de trabalhadores sem qualificação ou mesmo expulsos do mercado de trabalho. A maquinaria e a indústria moderna exacerbam a divisão entre uma pequena elite de trabalhadores qualificados e a massa desqualificada de trabalhadores. Esse movimento de desqualificação de uma grande massa de trabalhadores, colocados à margem do processo produtivo, não é algo estranho ao quadro contemporâneo do mundo do trabalho, muito bem-descrito por Harvey (2002) e que será tratado adiante.

Ainda seria preciso que Watt inventasse a máquina a vapor para que a emancipação da máquina fosse completa, pois até então a forçamotriz ficava na dependência de energias sobre as quais não havia completo controle por parte dos homens, como a força hidráulica e a força animal. Ambas, ademais, restringiam o campo de atuação da indústria (no caso da força hidráulica, que obrigava as indústrias a se localizarem à beira dos rios) ou dos animais (cuja vida produtiva como força motriz era curta em relação à máquina) e encarecia o processo, além de não ser garantia da continuidade e uniformidade nos movimentos para as máquinas.

Com a invenção da máquina a vapor, o capital consegue estabilidade na geração de energia e independência para ampliar as áreas de implantação das indústrias, dando origem ao processo de universalização das indústrias para todo o planeta. Outro resultado desse processo foi a concentração das indústrias nas cidades.

A máquina mecanizada supera a máquina-ferramenta, incorporando várias destas a seu mecanismo, dando outra conotação e 
realidade à produção. Neste caso, importa apontar o fim da subjetividade no processo de divisão do trabalho, em que, como na manufatura, o processo era ajustado ao trabalhador, dada a sua necessária boa relação com a ferramenta. Diz Marx:

Na produção mecanizada, desaparece esse princípio subjetivo da divisão do trabalho. Nela, o processo por inteiro é examinado objetivamente em si mesmo, em suas fases componentes, e o problema de levar a cabo cada um dos processos parciais e de entrelaçá-los é resolvido com a aplicação técnica da mecânica, da química etc., embora a teoria tenha sempre que ser aperfeiçoada pela experiência acumulada em grande escala. (MARX, 1998, p. 436)

Portanto, o novo modo de produzir, na maquinaria, contempla como princípio norteador a velocidade e os mecanismos típicos da máquina, aos quais os trabalhadores devem se adaptar para que possam produzir. Ao fazer isso, a produção dá mais um salto na exploração da mais-valia relativa, pois o ritmo de produção da máquina faz aumentar geometricamente a produção de cada trabalhador individual durante a jornada de trabalho.

Marx ainda avalia outras consequências da maquinaria sobre os trabalhadores, como é o caso do uso do trabalho infantil e das mulheres, possibilitado pelo fato de que a máquina prescinde da força física. Outros mecanismos utilizados contra o trabalhador, e que aqui somente serão citados, são o prolongamento da jornada de trabalho, a intensificação do trabalho, o aumento da velocidade das máquinas e a ampliação do número de máquinas por trabalhador.

A seguir, será analisado o conceito de redução ontológica, presente em Oliveira (2004), quando se pretende refletir teoricamente, com base nas premissas marxistas expostas, o movimento da realidade no que tange a formação do trabalhador para as demandas do trabalho na contemporaneidade.

\section{A REDUÇ̃̃O ONTOLÓGICA DO TRABALHADOR}

O conceito de "redução ontológica" encontra-se na instigante obra de Oliveira (2004), em que o autor procura analisar extensivamente a obra de Karl Marx em busca de apreender o conceito de exclusão, desde 
suas primeiras obras até $O$ Capital, incluindo os textos jornalísticos e cartas, objetivando, com isso, embasar teoricamente as ações das políticas públicas em relação ao combate à exclusão social.

Como é característico do método de Marx, Oliveira não trata do conceito de "redução ontológica" como algo isolado da totalidade de sua obra. $\mathrm{Na}$ verdade, essa redução é inerente ao processo de desenvolvimento do capital em todas as suas fases, processo este que sempre se caracterizou pela eliminação de todos os empecilhos ao seu desenvolvimento, em especial os "empecilhos" referentes aos homens concretos, nas suas atividades concretas, e a produção de valores de uso que satisfaçam suas necessidades, ou seja, a própria relação capital-trabalho.

É em O Capital que Marx alcança a maturidade metodológica, ao conseguir sintetizar o elemento oniparente dessa sociedade, o capital:

Na verdade, Marx aceita a pretensa autofundamentação do conceito "o capital", dispõe-se a experimentar uma forma de exposição hermética, em que todo o real seja subsumido por esse único conceito, na expectativa de poder revelar as deformações a que precisam ser submetidas certas realidades a fim de sujeitarem-se à lógica puramente econômica. (OLIVEIRA, 2004, p. 109)

O autor demonstra que, na linha de argumentação de $O$ Capital, Marx não poderia correr o mesmo erro de ter como parâmetro um elemento externo à sociedade, como aconteceu nos Manuscritos em relação ao conceito pressuposto da liberdade, erro este corrigido especialmente na Miséria da Filosofia (OLIVEIRA, 2004). Daí que, metodologicamente, Marx teria que partir de um elemento intrínseco à sociedade e viu no capital esse elemento que agrega todas as esferas sociais.

O modo de argumentação, que é a própria crítica de Marx, demonstra que o capital somente sobrevive pela exclusão de determinadas realidades, como as destacadas anteriormente. Essa exclusão se dá por um processo de deformação, que é o que Oliveira chama de "redução ontológica". Essa redução ou deformação ocorre porque, para que o capital sobreviva e se desenvolva, toda a sociedade deve estar submetida à sua lógica de funcionamento e, assim, todas as esferas sociais devem ser reduzidas ao quantitativo, ao econômico, inclusive o próprio homem. É essa redução do homem ao econômico que vamos aqui discutir, tendo Oliveira (2004) como base e visando a complementar os argumentos expostos no capítulo anterior. 
Antes, porém, é preciso salientar que o movimento de exclusão da realidade não é um movimento unívoco, mas dialético, ou seja, ele suporta um retorno, uma inclusão, que se dá de forma subordinada ao capital. Esse movimento de exclusão/inclusão não é senão um movimento orgânico ao capital, inerente ao seu desenvolvimento. É assim que o trabalhador concreto é excluído da argumentação burguesa e, no seu lugar, surge o "trabalhador coletivo", já analisado anteriormente. É assim também que o valor de uso é subsumido pelo valor de troca ou valor, e o trabalho concreto ao trabalho abstrato. E, por fim, é assim também que as relações sociais são fetichizadas pela mercadoria na sociedade capitalista.

Essa redução ontológica é analisada por Marx em termos da categoria aparecer (OLIVEIRA, 2004, p. 110) ou, segundo Kosik (1989), do concreto. Isso significa que ele parte do que é mais aparente na sociedade para alcançar, no final, o que lhe é estruturante, no caso, o capital. Esse é o modo como Marx construiu sua mais famosa obra, $O$ Capital, partindo justamente da mercadoria, relação que se encontra de forma mais aparente na sociedade. Essa aparência, porém, não significa obviedade, pois isso tornaria supérflua a ciência. Não é, no entanto, o caso de adentrar esse tema aqui. Basta fixar que o capital somente funciona sob a aparência da lógica da mercadoria enquanto princípio fundante da sociedade, o que é pura ficção que precisa ser revelada.

É sob essa ficção da mercadoria que todas as relações sociais capitalistas foram reduzidas à quantidade, ao econômico. E é nesse terreno que o próprio homem, como trabalhador, é também reduzido, assim como o trabalho concreto e o valor de uso, como já afirmado anteriormente. "Assim, Marx insiste em que a aparência da mercadoria enquanto forma elementar da riqueza é essencial para os próprios propósitos do capital” (OLIVEIRA, 2004, p. 112-113).

A aparência da mercadoria, diz Marx, é o seu valor de uso, que é o componente material da mercadoria em qualquer sociedade. No entanto, na sociedade capitalista, a mercadoria é também valor de troca. Esse valor de troca aparece, num primeiro momento, como relação quantitativa das proporções de valores de uso pelos quais as espécies são trocadas. Há aí uma ruptura entre o valor de troca, baseado na quantidade, e o valor de uso, baseado na qualidade. Acontece que, na troca, relação essencial na sociedade capitalista, as mercadorias não são consideradas 
pelo seu valor de uso, mas subsumidas apenas por seus valores de troca. O uso passa a ser secundário na relação social capitalista.

O fato do valor de troca não poder conter nenhum átomo de valor de uso significa que, numa estrutura econômica onde predomina o valor de troca, o valor de uso precisa ser excluído. Assim, excluído o valor de uso - por sua impossibilidade de ser incorporado no cálculo econômico - deve-se pagar o preço de ter que excluir do cenário todas as qualidades ligadas à materialidade das coisas, ou seja, é preciso abrir mão de compreender o real enquanto produto de uma rede complexa de relações sociais em múltiplas e mútuas determinações. (OLIVEIRA, 2004, p. 116)

Eliminar, portanto, o valor de uso, excluí-lo da análise, implica excluir a qualidade e permanecer apenas na quantidade do valor de troca. Simplifica-se, na aparência, a complexidade das relações sociais, até o ponto de simplificar o próprio homem, que passa a ser encarado como força de trabalho, em detrimento de todas as suas potencialidades humanas, reduzidas ao econômico, ao cálculo capitalista.

A eliminação do valor de uso da análise tem outra conseqüência, a qual nos interessa mais de perto nos limites aqui pretendidos, que é a desconsideração da qualidade do trabalho humano e a centralidade da sua quantificação. Daí adentrarmos na exclusão no capitalismo do trabalho concreto em prol do trabalho abstrato, genérico, o que é condição para a generalização da mercadoria como valor de troca e, portanto, de sua essência meramente econômica, quantificável. O trabalho, portanto, somente interessa ao capital como produtor de valor de troca, ou seja, foi reduzido de seu caráter concreto para um caráter abstrato, de produtor de valor de uso para produtor de valor de troca. É a redução do trabalho humano à força de trabalho.

O trabalho humano só pode figurar dentro do contexto da determinação econômica, ou seja, só pode ter sentido no papel de determinador de valor de troca, tendo já passado pela transformação da qualidade em quantidade, quer dizer, após ter sofrido uma redução ontológica [...] Esse trabalho humano, restringido tão-só a sua determinação quantitativa, constitui-se na importante descoberta de Marx, que vê apenas a possibilidade de descrevê-lo como força de trabalho. (OLIVEIRA, 2004, p. 121)

Esse é o movimento da redução ontológica do trabalhador, ou seja, movimento de esvaziamento do trabalho humano, subsumido pelo capital 
e transformado, ou melhor, deformado em mera força de trabalho. Assim, essa redução afeta o homem como um todo, já que o afeta em sua atividade fundamental, o trabalho. O homem concreto é descaracterizado em nome "do homem", uma abstração que proporciona o terreno do desenvolvimento do capital, que precisa transformar o mundo concreto em mera ficção. "Assim, a bem de efetivar-se, o capital tem que negar sua própria origem no homem concreto, cujo trabalho útil produz valores de uso" (OLIVEIRA, 2004, p. 123).

É assim que Marx pôde chegar a dizer que os homens transformaram-se em órgãos da maquinaria, ou seja, uma imagem que denota, com toda a força, o movimento de esvaziamento humano, deformado pela sua inserção no mundo da produção capitalista.

\section{ALGUMAS CONSIDERAC̣ÕES SOBRE A ATUALIDADE DE MARX}

O capital, como foi visto, tem como fundamento a negação das suas raízes concretas em favor de uma aparência abstrata, genérica, negação esta que, atualmente, está mais viva do que nunca e, portanto, é necessário entendê-la para realizar a sua crítica de forma mais qualificada.

O cenário atual, marcado pela acumulação flexível, demanda, para a formação dos trabalhadores, uma flexibilização determinada pelo lócus de cada um na cadeia produtiva. Essa flexibilização aparece, aos olhos do senso comum, como uma positividade absoluta, que repõe, no nível do discurso, a generalidade, o que implica que o trabalhador hoje deve constituir, por conta e risco próprios, uma relação mais densa e eficiente com o conhecimento para que possa se encaixar em uma faixa mais ampla do mercado de trabalho, ou seja, manter-se empregável.

A empregabilidade, atualmente, vem sendo utilizada, no âmbito do discurso capitalista, no sentido da responsabilização individual pelo sucesso ou fracasso na carreira (FERRET'TI, 2003). No Brasil, a burguesia industrial, reunida na CNI - Confederação Nacional da Indústria -, desde o início da década de 1990, vem propondo a categoria empregabilidade como central para a formação dos trabalhadores (CNI, 1993). Inclusive, essa proposição dos empresários foi incorporada na mais importante política de formação profissional do governo FHC, o PLANFOR - Plano Nacional de Qualificação do Trabalhador -, que durou de 1996 a 2003. 
A empregabilidade esconde, na verdade, o movimento de flexibilização e crise do capitalismo, que gera o desemprego em massa, e que nada mais é que uma faceta da redução ontológica no sistema de acumulação flexível (HARVEY, 2002), além de esconder a faceta destrutiva e excludente do mundo do trabalho na contemporaneidade (ALVES, 2007). Em vez de recolocar o homem nas suas potencialidades, essa flexibilização é apenas outra forma de subordinação do trabalhador ao capital e, desta feita, uma subordinação mais totalizante, que abrange a mente e o corpo do trabalhador por meio de sua subjetividade e pela continuidade do disciplinamento psicofísico constatado por Gramsci (1998) no fenômeno do americanismo e do fordismo.

Outra aparência do modelo atual de acumulação é a pretensa qualificação generalizada, substanciada pela base microeletrônica e a complexidade dos processos de produção instalados (KUENZER, 2003). $\mathrm{Na}$ verdade, se prosseguimos com Marx nas suas reflexões do Livro I de O Capital, verificamos que, na verdade, a introdução de máquinas cada vez mais produtivas e tecnologicamente avançadas significa o aumento no grau de desqualificação e perda do controle sobre os processos de produção por parte dos trabalhadores. Kuenzer (2002) denomina esse fenômeno como "polaridade das competências", categoria que indica que, na realidade, poucos trabalhadores passam a realizar trabalhos significativos, embora ainda subordinados ao capital, enquanto a massa dos trabalhadores é incorporada, sem qualificação e cada vez mais precariamente, no mercado de trabalho.

Outra faceta da redução ontológica, agora no campo educacional estrito, é o da emergência da pedagogia das competências ao longo dos anos de 1990. Nesse caso, ocorre um movimento mais amplo de subordinação da escola às necessidades não do trabalho, entendido ontologicamente, mas do mercado de trabalho, no sentido do lócus do trabalho abstrato, alienado. Essa subordinação é, no campo da academia, legitimada por teorias psicológicas, em especial pela emergência das teorias construtivistas (DUARTE, 2000; RAMOS, 2001; 2001a; SILVA, 2007). Tais teorias pedagógicas têm como fundamento a secundarização dos conteúdos escolares em nome de uma formação de base genérica, calcada no "aprender a aprender" e outros relacionados com uma formação subjetiva (caso do "aprender a ser") ou relacional (caso do "aprender a conviver"), ou mesmo de base instrumental (caso do 
“aprender a fazer”). Há, segundo Ramos (2001; 2001a) e Ribeiro (2007), uma aproximação mais recente das competências com o construtivismo.

Segundo Ramos (2001a), a adoção das competências como paradigma pela escola a relaciona às demandas do mercado de trabalho, no sentido de contemplar demandas específicas do trabalho a ser realizado, em matéria de competências. Nesse sentido, as competências são vislumbradas pelos industriais brasileiros como o objetivo da educação subordinada às necessidades da indústria.

O setor produtivo requer trabalhadores cada vez mais capacitados e qualificados. Disso decorre a necessidade de identificar quais as competências dos perfis profissionais desenhados para atender às novas demandas da indústria. O processo não é estanque, mas de grande sinergia: assim como a educação contribui para o avanço da indústria, esta, por sua vez, retribui provocando mudanças no ambiente educativo. (CNI, 2007, p. 8)

No que se refere à educação básica, os industriais demandam a formação das chamadas "competências básicas", ou seja, aquelas que dão suporte para as demais competências, inclusive para as específicas das profissões, e porque são competências que permitem o aprendizado por toda a vida, ou seja, são competências que permitem o "aprender a aprender".

Desse modo, verifica-se uma estreita relação entre as competências, a subordinação da educação formal aos interesses do capital e, por outro lado, o uso dos recursos psicológicos para esse fim. Assim, opera-se no campo educacional uma redução ontológica do homem ao trabalhador alienado, ou seja, à sua esfera econômica nos termos referidos por Oliveira (2004). Esse cenário pode ser percebido pela retomada e pela atualização, pela burguesia industrial, da teoria do capital humano, que embasa o mais recente programa da $\mathrm{CNI}$, intitulado "Educação para a Nova Indústria" (CNI, 2007). Para a Teoria do Capital Humano, o homem se reduz não apenas a um órgão da máquina, mas sim a um instrumento para a competitividade da indústria, em redução ontológica.

Para finalizar, acreditamos que o movimento de qualificação/ desqualificação dos trabalhadores é mais corretamente compreendido se o cenário atual for analisado pelos instrumentos metodológicos aqui apontados, especialmente o resgate das análises de Marx no Capítulo I de 
O Capital, em que o autor analisa detidamente o desenvolvimento das forças produtivas desde a cooperação até a maquinaria, construindo um retrato do desenvolvimento da classe trabalhadora e de sua relação com os conhecimentos e habilidades necessários para a produção em cada período, o que Gramsci (1991) denominou de "princípio educativo". Por outro lado, o uso da categoria de redução ontológica de Oliveira (2004) mostrou-se eficiente para a análise aqui empreendida, devido ao fato de ser uma leitura teórica coerente com o movimento de progressiva desqualificação dos trabalhadores, reduzidos, desde sempre, à esfera do econômico e do utilitarista, segundo as conveniências do capital em cada período.

O retorno à história da desqualificação dos trabalhadores, à sua "redução ontológica" (OLIVEIRA, 2004), a meros braços da máquina capitalista, é necessário para se entender o cenário atual, que mantém uma linha contraditória e dinâmica de continuidade com o processo histórico já apontado por Marx n'O Capital.

\section{REFERÊNCIAS}

ALVES, G. Dimensões da reestruturação produtiva - Ensaios de Sociologia do Trabalho. Londrina: Práxis, 2007.

BOITO JR., A. Pré-capitalismo, capitalismo e resistência dos trabalhadores. Crítica Marxista, São Paulo, n. 12, p. 77-104, maio/ 2001.

CONFEDERAÇÃO NACIONAL DA INDÚSTRIA. Educação para a nova indústria: uma ação para o desenvolvimento sustentável do Brasil. Brasília: CNI, 2007.

EVANGELISTA, J.E. Crise do marxismo e irracionalismo pós-moderno. São Paulo: Cortez, 1997.

FERRERTI, Celso et. Al. Escola e fábrica: vozes de trabalhadores em uma indústria de ponta. Cadernos de Pesquisa, n. 118, São Paulo, mar. 2003.

GRAMSCI, A. Americanismo e fordismo. In: GRAMSCI, A. Maquiavel, a política e o estado moderno. Rio de Janeiro: Civilização Brasileira, 1988.

GRAMSCI, A. Os intelectuais e a organização da cultura. 8 ed. Rio de Janeiro: Civilização Brasileira, 1991.

HARVEY, D. A condição pós-moderna. 11 ed. São Paulo: Loyola, 2002.

HOBSBAWM, Eric J. Os Trabalhadores: estudos sobre a história do operariado. 2 ed. Rio de Janeiro: Paz e Terra, 2000b.

KLEIN, L.R. Trabalho, educação e linguagem. Educar em Revista, Especial, p. 15-42, 2003. KOSIK, K. Dialética do concreto. 5 ed. Rio de Janeiro: Paz e Terra, 1989.

KUENZER, A. Z. A pedagogia da fábrica: as relações de produção e a educação do trabalhador. São Paulo: Cortez, 1985.

KUENZER, A. Z. Exclusão includente e inclusão excludente: a nova forma de 
dualidade estrutural que objetiva as novas relações entre educação e trabalho. In: LOMBARDI, Claudinei; SAVIANI, D.; SANFELICE, J.L. (Orgs.). Capitalismo, trabalho e educação. Campinas: Autores Associados, HISTEDBR, 2002. p. 77-96.

KUENZER, A. Z. As relações entre conhecimento tácito e conhecimento científico a partir da base microeletrônica: primeiras aproximações. Curitiba. Educar em Revista, Especial, p. 43-69, 2003.

MARX, K. O Capital, Livro I. Rio de Janeiro: Civilização Brasileira, 1998.

OLIVEIRA, A.R. Marx e a exclusão. Pelotas: Seiva, 2004.

OLIVEIRA, E. Toyotismo no Brasil: desencantamento da fábrica, envolvimento e resistência. São Paulo: Expressão Popular, 2004.

RAMOS, M.N. A pedagogia das competências: autonomia ou adaptação? São Paulo: Cortez, 2001.

RAMOS, M.N. A pedagogia das competências e a psicologização das questões sociais. São Paulo. Boletim Técnico do SENAC. v. 27, n. 3, Set/Dez 2001a.

SILVA, M.R. Currículo e competências: a formação administrada. São Paulo: Cortez, 2007.

SMITH, A. A riqueza das nações: investigação sobre sua natureza e suas causas. V. 1. São Paulo: Nova Cultural, 1985.

THOMPSON, Edward Palmer. Um exército de justiceiros. In: THOMPSON, E. P. A Formação da Classe Operária Inglesa. V. 3: A Força dos Trabalhadores. 3 ed. Rio de Janeiro: Paz e Terra, 2002.

\section{NOTA}

${ }^{1}$ Claro está que, com esta afirmativa, estamos negando toda a história de resistência da classe trabalhadora. Apenas se quer afirmar os objetivos dos capitalistas no desenvolvimento técnico das forças produtivas. Para um estudo aprofundado sobre a resistência dos trabalhadores, ver BOITO Jr. (2000), HOBSBAWM (2000), THOMPSON (2002), entre outros.

Recebido: 07/08/2008

Aprovado: 19/03/2009

Contato:

Universidade Estadual do Centro-Oeste (UNICENTRO)

Departamento de Pedagogia

Rua Salvatore Renna - Padre Salvador, 875 - Santa Cruz

(antiga Rua Presidente Zacarias de Góes)

Guarapuava - PR

CEP 85015-430 